\title{
Influence of matrix toughness and interfacial strength on the toughness of epoxy composites with ductile steel fabric reinforcement
}

Jana Christine Faes, Ali Rezaei, Wim Van Paepegem \& Joris Degrieck

To cite this article: Jana Christine Faes, Ali Rezaei, Wim Van Paepegem \& Joris Degrieck (2015) Influence of matrix toughness and interfacial strength on the toughness of epoxy composites with ductile steel fabric reinforcement, Composite Interfaces, 22:8, 779-793, DOI: 10.1080/09276440.2015.1076639

To link to this article: $\mathrm{http}: / / d x . d o i . o r g / 10.1080 / 09276440.2015 .1076639$

曲 Published online: 14 Aug 2015.

Submit your article to this journal $\pi$

Щ Article views: 25

View related articles $₫$

View Crossmark data $\asymp$ 


\title{
Influence of matrix toughness and interfacial strength on the toughness of epoxy composites with ductile steel fabric reinforcement
}

\author{
Jana Christine Faes ${ }^{\mathrm{a}, \mathrm{b} *}$, Ali Rezaei ${ }^{\mathrm{a}, \mathrm{b}}$, Wim Van Paepegem ${ }^{\mathrm{a}}$ and Joris Degrieck ${ }^{\mathrm{a}}$ \\ ${ }^{a}$ Faculty of Engineering and Architecture, Department of Materials Science and Engineering,

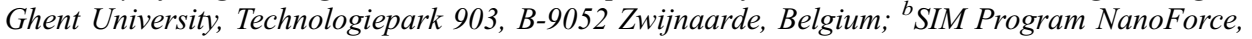 \\ Technologiepark 935, B-9052 Zwijnaarde, Belgium
}

(Received 29 May 2015; accepted 14 July 2015)

\begin{abstract}
In the last decades, several studies have been performed on polymers reinforced with steel cords or wires. However, the diameter of these steel reinforcements was still quite large (200 $\mu \mathrm{m}$ and more). Recently, stainless steel fibres were developed with a diameter down to $30 \mu \mathrm{m}$, which makes it possible to process steel fibre-reinforced composites in a similar way as carbon- or glass fibre-reinforced composites. If a proper combination of the ductile steel fibre and a ductile polymer is chosen, a ductile composite should be achieved. This article reports on the influence of the matrix toughness and the fibre/matrix adhesion strength on the ductility of the resulting steel fibre-reinforced textile composite. Tensile tests have been combined with microscopic analysis to investigate the relation between the mechanical behaviour and the observed damage morphology. It was found that distributed damage increases the toughness in a textile composite, because it softens the transversal structure that interlocks the ductile load-bearing yarns. This explains the counterintuitive observations regarding the influence of the matrix ductility and the fibre/matrix adhesion strength on the composite toughness. It was found that selecting a brittle epoxy matrix can lead to a ductile composite, because of the widely spread and dense cracking pattern that allows more strain on the ductile steel fibres. If the fibre-matrix adhesion is enhanced by introducing a silane coupling agent to the fibre surface, transversal cracks are prevented and the ductility of the composite drops drastically. These results for the textile composites are contrary to earlier findings on the UD and cross-ply counterparts.
\end{abstract}

Keywords: textile composite; ductile fibres; composite toughness; damage morphology

\section{Introduction}

The use of a polymer matrix composite as a structural component is typically considered when a high stiffness and strength are required and the weight limitations are stringent. The design is in these cases limited to the linear elastic regime, as these composites have a low ductility, characterized by brittle failure at a low strain level. A way to enhance the deformation capability is to replace the traditional, brittle carbon or glass fibres by more ductile fibres. In this context, the recent developments in stainless steel fibre production technology are interesting. A fibre diameter of $30 \mu \mathrm{m}$ or less can be achieved nowadays, and the strain-to-failure can be tailored within a wide range through heat treatment. Whereas the more ductile polymeric or natural fibres often fall

\footnotetext{
*Corresponding author. Email: jana.faes@ugent.be
} 
short when it comes to stiffness, steel fibres can compete with glass fibres in this regard. Previous research on stainless steel fibre composites has shown that the expectations regarding stiffness and failure strain can be met for unidirectional and cross-ply reinforcement.[1-3] Callens et al. found that the toughness of these composites can even be increased through chemical enhancement of the fibre/matrix adhesion strength [2] or by selecting a more ductile matrix system.[3]

This study investigates the influence of the fibre/matrix interface and the matrix ductility in case when 4-harness satin weave reinforcement is used. The interaction between yarns and matrix is much more complex in a textile composite, and this changes the micro-mechanical processes that control the macroscopic mechanical behaviour. Especially with ductile fibres, the geometry of the reinforcement determines to what extent the plastic potential is exploited.[4] Two epoxy matrix systems are considered in this study, one brittle, and the other ductile. The naturally weak steel/polymer adhesion strength is improved by introducing a silane coupling agent to the fibre surface. Static tensile tests will be performed in order to establish the macroscopic mechanical behaviour of the composites. The failure mechanisms will be investigated by microscopic analysis of the damage morphology.

\section{Materials}

Three composites were investigated in this study. All three have the same steel fabric reinforcement and the same lay-up system, and all three were produced in-house using vacuum assisted resin transfer moulding (VA-RTM). The difference between the three composites is in the matrix system (tough/brittle) and in the fibre-matrix interface (untreated/enhanced). To distinguish between the combinations that are considered in this study, following naming conventions are introduced: TU - tough matrix, untreated interface; BU - brittle matrix, untreated interface; and TT - tough matrix, treated interface.

\subsection{Ductile reinforcement}

The fabric reinforcement that was used stands out because of its ductility. It consists of annealed stainless $316 \mathrm{~L}$ steel fibres with a filament diameter of about $30 \mu \mathrm{m}$. The fibres were manufactured by NV Bekaert SA by drawing a tube containing several coppercoated steel wires to a smaller diameter. The covering tube and the copper are then dissolved in acid, resulting in individual steel fibres. As a consequence of this bundle drawing process, the fibre cross sections are irregular, rather than round (Figure 1(a)). After drawing, the fibres are annealed at over $800{ }^{\circ} \mathrm{C}$ in order to increase the ductility. A failure strain as high as $19.5 \%$ was found in the single-fibre tensile experiments performed by the manufacturer. Other specifications of the steel fibres can be found in Table 1. The ductile fibres were woven into a 4-harness satin weave (Figure 1(b)) with an areal density of $1455 \mathrm{~g} / \mathrm{m}^{2}$ and a thickness of $0.8 \mathrm{~mm}$. The warp yarns consist of 275 fibres and the weft yarns are composed of two warp yarns.

\subsection{Matrix systems}

The brittle matrix system was obtained by combining bisphenol-A resin EPIKOTE ${ }^{\mathrm{TM}}$ 828 with a 1,2-diaminocyclohexane curing agent, mixed in a 100:15.2 weight ratio. The resin was obtained from Brenntag N.V., and the curing agent was purchased from 

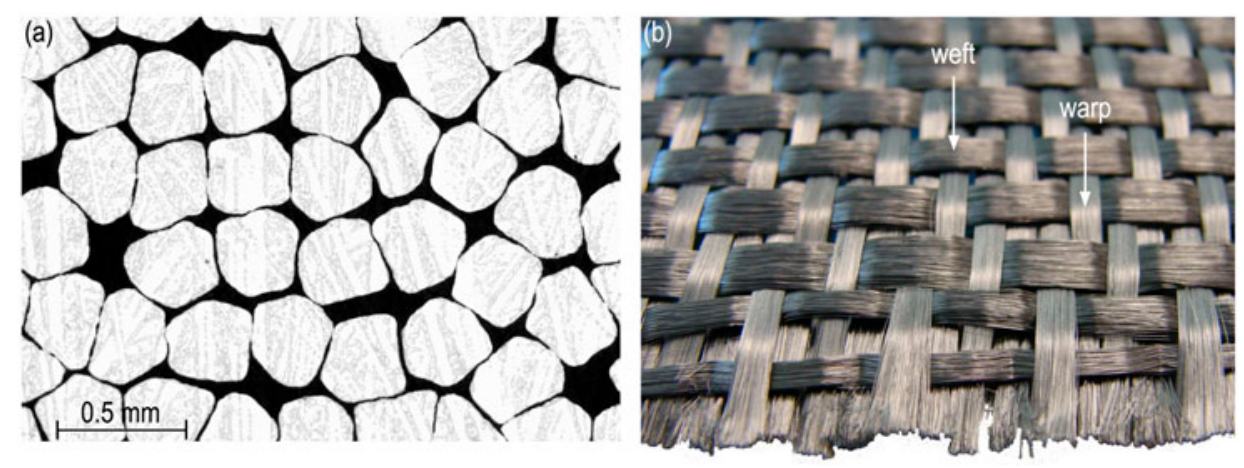

Figure 1. SEM image of the steel fibres (a) and the stainless steel fibre 4-harness satin weave reinforcement fabric (b).

Table 1. Tensile properties of the ductile stainless steel fibres and the two matrix systems.

\begin{tabular}{lccc}
\hline Mechanical property & $\begin{array}{c}\text { Fibres }^{\mathrm{a}} \\
\text { Value }\end{array}$ & $\begin{array}{c}\text { Tough epoxy } \\
\text { Value }\end{array}$ & $\begin{array}{c}\text { Brittle epoxy }^{\mathrm{c}} \\
\text { Value }\end{array}$ \\
\hline Young's modulus (GPa) & 193 & $2.73 \pm 0.02$ & 2.9 \\
Yield strength (MPa) & 345 & $41.4 \pm 2.4$ & NA \\
Tensile strength (MPa) & 667 & $66.1 \pm 0.4$ & 75 \\
Failure strain (\%) & $19.5 \pm 5.1$ & $8.24 \pm 0.69$ & 4 \\
\hline
\end{tabular}

${ }^{\mathrm{a}}$ Data obtained from NV Bekaert SA.

${ }^{\mathrm{b}}$ Data obtained from Allaer et al. [1].

${ }^{\mathrm{c}}$ Data obtained from Callens et al. [3].

Sigma-Aldrich. The tough matrix system is a low-viscosity resin system developed for vacuum infusion moulding of wind turbine blades. It consists of the modified bisphenol-A resin EPIKOTE ${ }^{\mathrm{TM}}$ MGS $^{\mathrm{TM}}$ RIMR 135 and the polyamine curing agent EPIKUR$\mathrm{E}^{\mathrm{TM}} \mathrm{MGS}^{\mathrm{TM}}$ RIMH 137, both purchased from Momentive Specialty Chemicals. Resin and harder were mixed in a 100:30 weight ratio. The tensile properties of both epoxies are summarized in Table 1.

\subsection{Interface modification}

An enhancement of the fibre-matrix interface was achieved by introducing a GPS (3-glycidoxypropyltrimethoxysilane) coupling agent to the fibre surface. The GPS molecules act as a covalent chemical bridge between the stainless steel fibre surface and the epoxy matrix, hence increasing the adhesion. The silanes were applied to the fibre surface through a wet chemical deposition procedure that was especially optimized to improve the bonding between epoxy and stainless steel.[5-7] First, impurities were removed from the fibre surface. To this end, the fabric was cleaned ultrasonically in ethanol for $15 \mathrm{~min}$. The ethanol was rinsed off with deionized water, and the fabric was dried with clean compressed air. The second step is the hydrolysis of the silanes in a dilute aqueous solution, to form active silanol $(\mathrm{Si}-\mathrm{OH})$ groups that can adsorb to the fibre surface (Figure 2(a), left). The composition of the solution plays an important role in the amount of self-condensation of the silanol groups prior to deposition (Figure 2(a), 
(a)<smiles>[X]O[Si]([Y])(O[X])O[X]</smiles>

(b)<smiles>[Y][Si](O)(O)O</smiles>

(c)<smiles>[Y][R]O[Si]([Y])(O)O[R]</smiles><smiles>[Y][R](O)(O)OCC(C)C(C)CCO</smiles><smiles>[Y][R][Si](O)(O[R]([Y])(O)O)O[Si]([R])(O)O</smiles>

$\mathrm{H}_{2} \mathrm{O}$<smiles>[Y][Si](O)(O)O[Si](O)(O)O[Si]([R])(O)O</smiles>

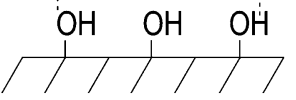

metal surface

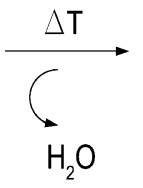

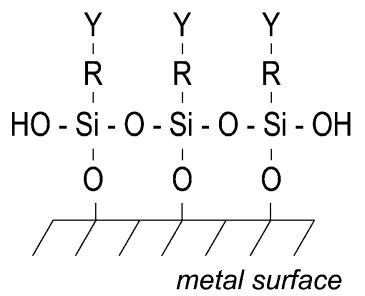

Figure 2. Wet chemical deposition of silane surface treatment on the steel fibre surface: reaction scheme.[6]

right). As self-condensation consumes hydroxyl groups that are necessary for coupling to the fibre surface, it must be kept to a minimum. The silane solution that was used in this study was prepared by adding $2 \mathrm{v} \%$ of GPS to a mixture of deionized water $(90 \mathrm{v}$ $\%$ ) and ethanol $(10 \mathrm{v} \%)$. The $\mathrm{pH}$ of the solution was brought down to 5 . The third deposition step is to dip the steel fabric reinforcement into the solution, so that hydrogen bonds can form between the silane hydroxyl groups and the metal hydroxyl groups (Figure 2(b)). A dipping time of $30 \mathrm{~s}$ was applied, after which the fabric was rinsed with ethanol for $60 \mathrm{~s}$ to remove loosely bound molecules. The last step is to dry the fabric for $90 \mathrm{~min}$ at $70{ }^{\circ} \mathrm{C}$ to facilitate the condensation reaction. In this step, the silanol groups further covalently bond with the fibre surface and with each other to form, respectively, metal-siloxane $(\mathrm{Si}-\mathrm{O}-\mathrm{M})$ bonds, and a siloxane network ( $\mathrm{Si}-\mathrm{O}-\mathrm{Si}$ ) (Figure 2(c)). The reinforcement was used for laminate production immediately after finishing the deposition process in order to avoid ageing of the coating.

\subsection{Composite plate production}

Composite plates with dimensions of $330 \times 330 \times 3 \mathrm{~mm}^{3}$ were produced using the VA-RTM technique. For both matrix systems, the mix of resin and hardener was 
degassed in a vacuum bell jar, after which it was drawn through a stacking of dry fabric under vacuum pressure. All textile layers were aligned manually and with the same orientation. The tough matrix system was cured at room temperature for $24 \mathrm{~h}$, followed by $15 \mathrm{~h}$ at $80^{\circ} \mathrm{C}$. The brittle matrix composites were cured at $70{ }^{\circ} \mathrm{C}$ for $1 \mathrm{~h}$ and post-cured at $150{ }^{\circ} \mathrm{C}$ for $1 \mathrm{~h}$. Microscopic analysis showed no sign of poor fibre impregnation or air entrapments. The overall fibre volume fraction of the composite laminates was determined at $26 \%$ using the principle of Archimedes in accordance with the ASTM D 792-08 standard [8] in combination with a rule of mixtures,[9] and at $24 \%$ based on the areal density of the fabric and the plate thickness. An approximation of the directional fibre distribution was found by counting the number of yarns running along warp and weft over a square area of the plate surface. This calculation reveals that the warp direction accounts for $52.5 \%$ of the fibre volume fraction.

\section{Experimental testing procedure}

\subsection{Methodology}

Static tensile experiments were carried out in accordance with the ASTM D3039/ D3039M standard [10] on all three composites and in both orthotropic laminate directions. For every set of experiments, four rectangular test coupons were cut from the composite plates. Specimen dimensions and experimental instrumentation are illustrated in Figure 3.

Every coupon was equipped with a strain gauge with a resistance of $350 \Omega$ and a maximum strain of $5 \%$ in order to measure the local strains in the gauge area along the loading direction. The resistance wire of the strain gauge covers an area of $3 \times 7 \mathrm{~mm}^{2}$, so the measurement made by the strain gauge is the average longitudinal strain over this region. This is an important note, because the surface strains in fabric reinforced composites are typically non-uniform. In order to get a view on the full-field surface displacements and deformations, the TU specimens were additionally instrumented with stereovision Digital Image Correlation (3D-DIC) (Figure 3(a)).[11,12] The principle

(a)

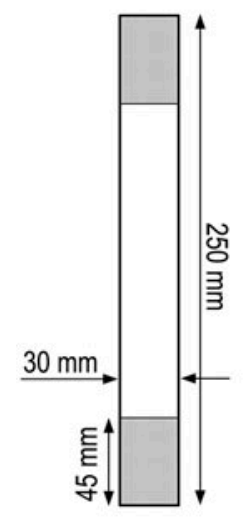

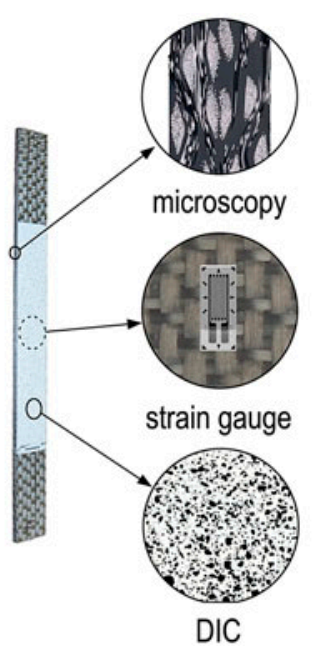

(b)

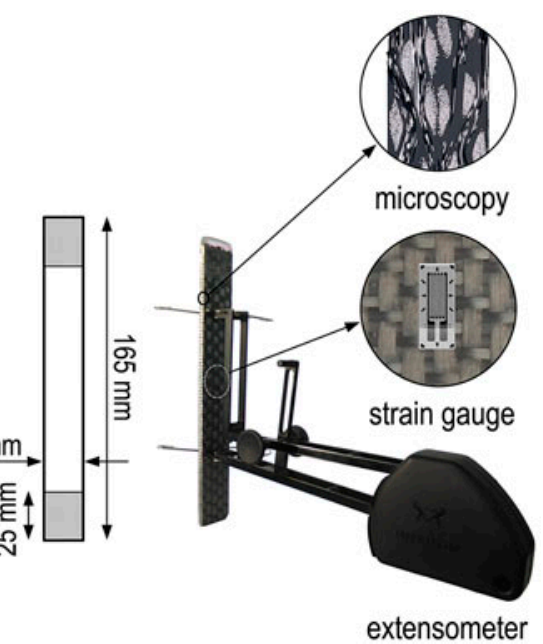

Figure 3. Measurements and instrumentation for TU (a) and TT/BU (b) tensile specimens. 
behind this technique is to monitor a speckle pattern on the specimen surface during loading and to calculate the full surface strain fields afterwards by correlating the consecutive images. A two camera stereovision set-up was chosen over a single camera set-up, because it can measure out-of-plane motions of the specimen surface during the test. Pictures of the speckled specimen surface were taken every second by two 2 megapixel 8-bit CCD AVT Stingray F-201 B1/1.8" cameras, and all post processing was performed with the MatchID software application.[13] The camera system was calibrated in order to account for intrinsic and extrinsic parameters during the image correlation process. In addition to providing a view on the surface strain distribution, the DIC results can be used to verify the strain gauge measurements. To this end, the DIC longitudinal strain map was averaged out over the same $3 \times 7 \mathrm{~mm}^{2}$ working area as the strain gauge and on the same position. The BU and TT specimens were instrumented with an extensometer with a gauge length of $80 \mathrm{~mm}$ and a range of $100 \%$ (Figure 3(b)). The extensometer takes over the strain measurement when the strain gauge reaches the limit of its working range or when it fails due to brittle surface cracks. Due to the larger gauge length, it also provides a more global view on the strain in case there is damage localization. The specimens were polished on one edge for microscopic analysis of the damage morphology. The BU and TT specimens had dimensions of 165 by $20 \mathrm{~mm}^{2}$, the TU specimens were cut 250 by $30 \mathrm{~mm}^{2}$ to provide a larger window for the DIC measurements. Preliminary testing had shown that the specimen size does not influence the results.

The experiments were performed on a servo-hydraulic INSTRON 8801 testing machine with a AlignPRO alignment fixture. The tests were displacement-controlled with a constant crosshead speed of $2 \mathrm{~mm} / \mathrm{min}$. Force and displacement were given by the FastTrack 8800 digital controller with the same time sampling. Measurements by the strain gauge and the extensometer were acquired synchronously using Labview data acquisition software. After the experiment, the damaged specimen edge was reconstructed over its full length through 3D image stitching with a Keyence VHX-2000 microscope. The surface was first captured piece-by-piece on separate microscopic images. Then, these images were stitched together by software, creating a field of view up to $20 \mathrm{~cm}^{2}$. The focal length is varied between pre-chosen limits while capturing the microscopic pictures. This ensures a sharp result, even if the specimen edge is tilted or uneven. All results published in the next section refer to coupons that failed in the mid-section of the gauge area, sufficiently far away from the clamps.

\subsection{Results and discussion}

\subsubsection{Stress-strain response}

Figure 4(a)-(c) shows the stress-strain acquisitions for the three composites tested along the warp direction, and Figure 4(d) provides an overview for comparison. The most notable difference between the three materials is the ultimate tensile strain, ranging from less than $1 \%$ for the most brittle composite to almost $5 \%$ for the toughest one. The failure stress and strain along the warp direction can be found in Table 2, along with the Young's modulus and the $0.1 \%$ offset yield point. All mechanical constants were derived from strain gauge measurements, unless specified otherwise. The Young's moduli were calculated based on the slopes of the least-squares linear regression fits on the stress-strain curves up to $1500 \mu \varepsilon$. The recommendation in the ASTM D3039/D3039M standard [10] to extract the Young's modulus between 1000 and 

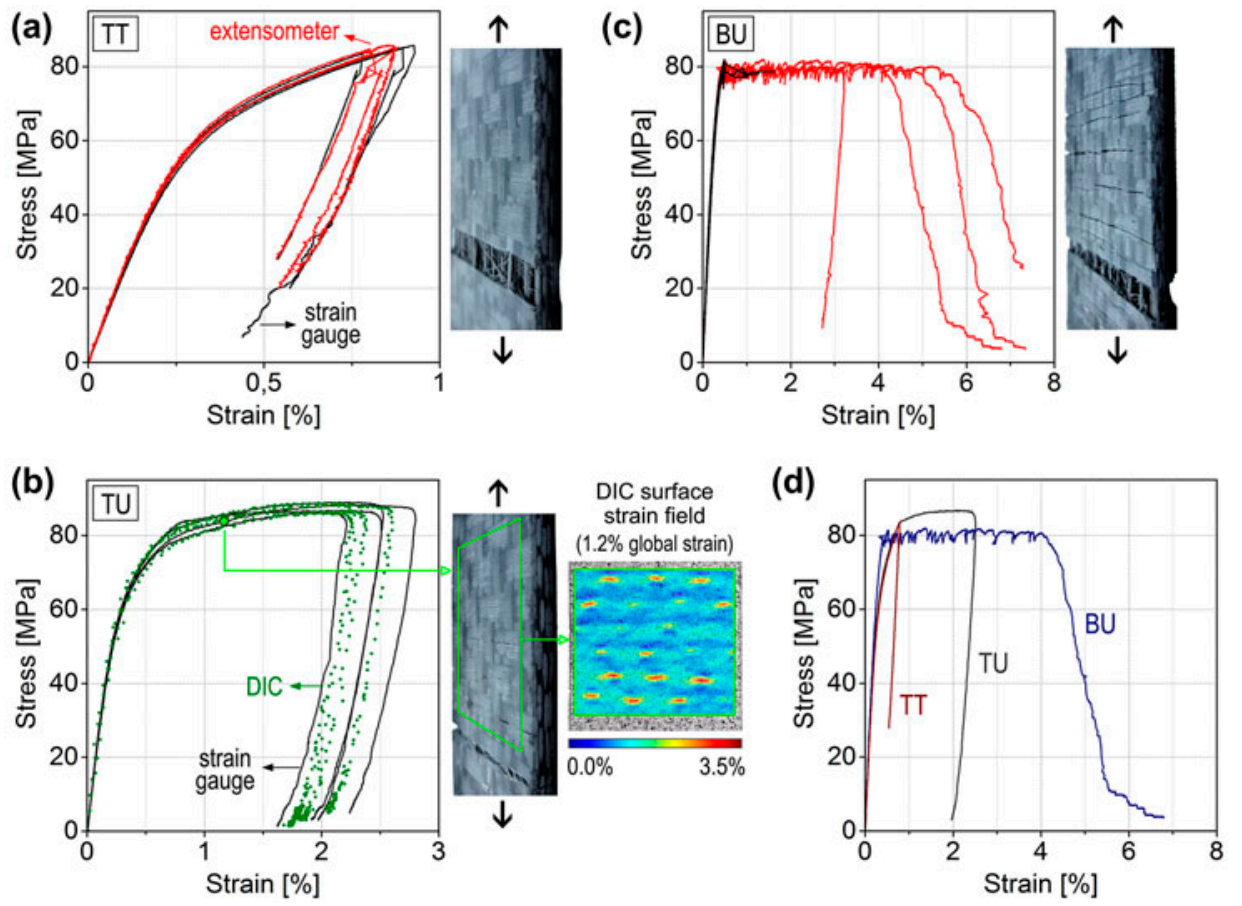

Figure 4. Stress-strain response and surface cracks under warp-oriented tensile loading for the TT (a), TU (b) and BU (c) composite specimens, and a comparative overview of the stress-strain response of all three composites (d).

Table 2. Tensile properties along the warp direction of steel fabric composites with brittle (B) or tough $(\mathrm{T})$ epoxy matrix and with untreated $(\mathrm{U})$ or treated $(\mathrm{T})$ interface.

\begin{tabular}{lccc}
\hline & TT & TU & BU \\
Mechanical property & Value & Value & Value \\
\hline Young's modulus $E(\mathrm{GPa})$ & $24.5 \pm 1.6$ & $26.0 \pm 0.7$ & $25.8 \pm 1.5$ \\
Yield strength $\sigma_{\mathrm{Y}, 0.1 \%}(\mathrm{MPa})$ & $65.1 \pm 1.5$ & $64.4 \pm 0.8$ & $76.3 \pm 0.5$ \\
Yield strain $\varepsilon_{\mathrm{Y}, 0.1 \%}(\%)$ & $0.37 \pm 0.01$ & $0.35 \pm 0.01$ & $0.40 \pm 0.02$ \\
Ultimate tensile strength $\sigma_{\text {ult }}(\mathrm{MPa})$ & $85.1 \pm 1.1$ & $87.7 \pm 1.2$ & $80.9 \pm 0.8$ \\
Ultimate tensile strain $\varepsilon_{\text {ult }}(\%)$ & $0.85 \pm 0.07$ & $2.51 \pm 0.24$ & $4.81 \pm 1.33^{\mathrm{a}}$ \\
\hline
\end{tabular}

${ }^{a}$ Maximum strain value with a stress level within $10 \%$ of the ultimate stress, as recorded by the extensometer.

$3000 \mu \varepsilon$ was not followed, because the TT and TU composites exhibit a non-linear stress-strain response starting from approximately $1500 \mu \varepsilon$.

The TT composite appears to be the most brittle of the three composites. The stress-strain curves on Figure 4(a) can be divided into three regions. After a short elastic region up to a strain of approximately $0.15 \%$, a region of increasing softening sets in. At an average strain of $0.85 \%$, one single brittle transversal crack causes a sudden loss of load-bearing capacity. The crack is bridged by warp fibres which continuously ravel out when further straining is applied, a phenomenon that is responsible for the downward region after failure. Apart from the fatal crack, the specimen surface shows 
no signs of damage after loading. The TU composite (Figure 4(b)) initially exhibits the same stress-strain relation as the TT composite. As is clear on the overview in Figure 4(d), the stress-strain curves of both composites coincide until the TT composite fails. The TU specimens can be strained about three times further, under a nearly constant stress. During this stress plateau, transversal cracks appear on the specimen surface and evenly spread along the length of the specimen. The DIC surface strain fields show large strain concentrations at the crack locations, i.e. at the centre of the surface weft yarns. At a global strain of $1.2 \%$, local surface strains reach up to $3.5 \%$, corresponding to a concentration factor of 2.9. As more strain is applied, the surface cracks open up uniformly, and they never jump a crimp region. Even after failure, no surface cracks were found that had crossed a warp yarn. At an average global strain of $2.51 \%$, the deformation localizes in one crack zone and the load-bearing capacity is lost. In this composite as well, the fatal crack is bridged by warp yarns that continue to carry some residual load as they are pulled out of the matrix. The toughest behaviour is accomplished by the BU composite (Figure 4(c)). The stiffness of this composite is not significantly different than that of the other two composites, but the stress-strain curves remain steeper after the initial elastic region. This translates into higher values for the $0.1 \%$ offset yield stress and strain (Table 2). Thereafter, the steep initial part of the stress-strain curve abruptly passes into a jagged plateau. Every time the tensile strength is reached, a brittle, yet non-fatal crack causes a short fall in the stress-strain curve. The cracks propagate easier than the ones noticed in the TU composite. As soon as
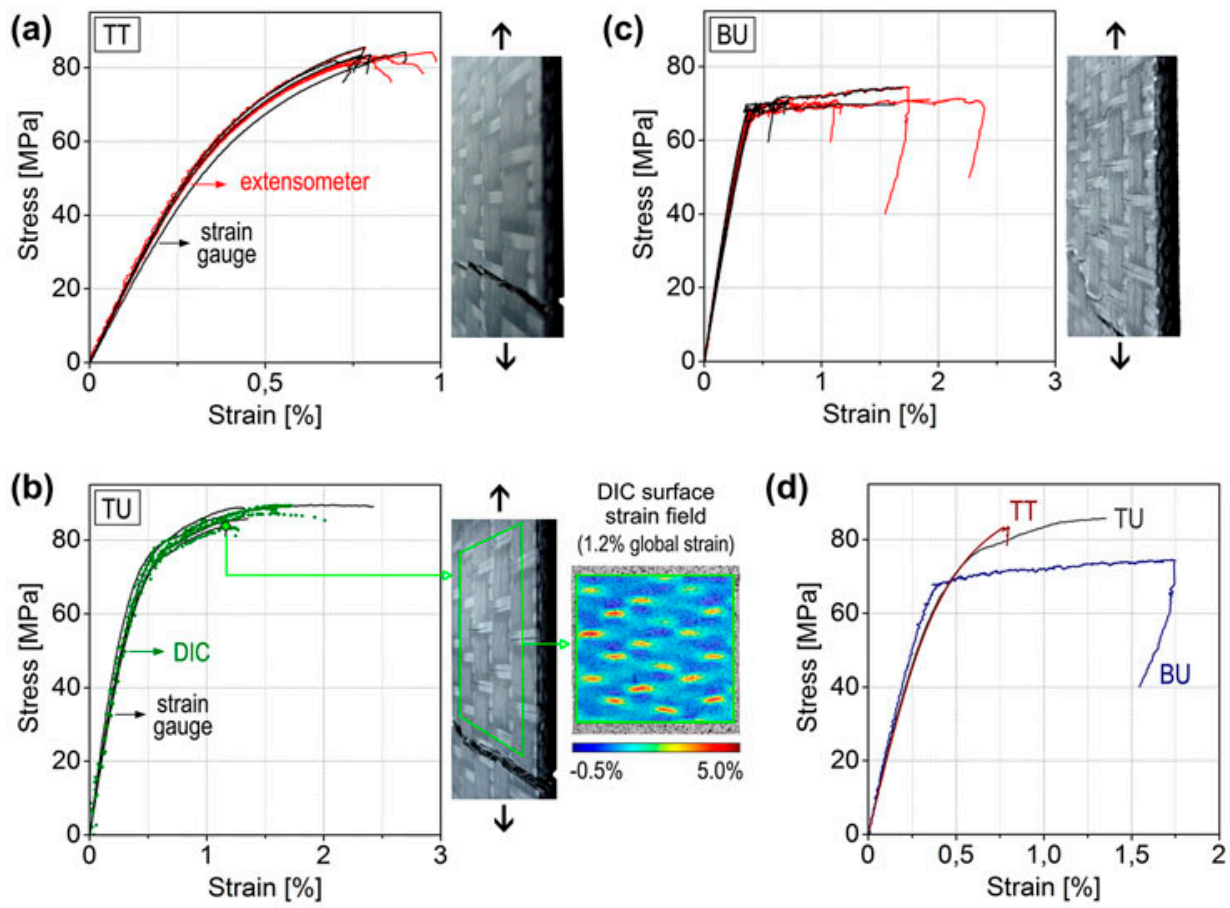

Figure 5. Stress-strain response and surface cracks under weft-oriented tensile loading for the TT (a), TU (b) and BU (c) composite specimens, and a comparative overview of the stress-strain response of all three composites (d). 
one of them crosses the strain gauge, the resistance wire breaks and the strain recording fails. Therefore, only the extensometer captures the full toughness of this material. Similar as for the TU specimens, cracks run through the centres of the surface weft yarns and they are evenly distributed over the length of the specimen. In the BU specimens, however, more cracks appear with greater lengths - they easily jump the crimp regions, and they open up further. Crack localization does not occur in this composite until a strain of $4.8 \%$ is reached.

Similarly as for the experiments along the warp direction, the stress-strain acquisitions for the three composites tested along the weft direction are shown in detail on Figure 5(a)-(c), and a comparative overview is given in Figure 5(d). Mechanical tensile properties are listed in Table 3. They were calculated based on strain gauge measurements, unless specified otherwise. The Young's moduli were extracted via the same procedure as for the warp-oriented specimens in order to enable comparison.

Some distinct differences between warp- and weft-oriented loadings may be noticed when comparing the stress-strain behaviour and the mechanical properties that were derived from it. A comparative overview is given in Figure 6(a) for the TT composite, in Figure 6(b) for the TU composite, and in Figure 6(c) for the BU composite. First of all, the average Young's modulus along the warp is more than $25 \%$ higher than along the weft (25.5 GPa compared to $20.0 \mathrm{GPa}$, respectively). Only a small part of this difference can be attributed to the slightly higher fibre volume fraction along the warp direction (cf. Section 2.4, the warp direction accounts for $52.5 \%$ of the fibre volume fraction). The main reason is the larger crimp angle of the weft yarns. The loadcarrying yarns contribute most to the stiffness when they are aligned with the load, so the stronger the yarn undulations, the more they lower the stiffness. The higher crimp angle in the weft yarns is also reflected in the DIC surface strain fields on Figure 5(b). At a global tension of $1.2 \%$, the strain magnifications in the crimp region reach up to $5 \%$. The corresponding strain concentration factor is 4.2 , while a value of 2.9 was found in the warp-oriented composite (Figure 4(b)). Another difference between the loading directions is the failure mechanism. Unlike the warp yarns, the weft yarns do no bridge the fatal crack. As a result, there is no post-failure residual strength due to fibre pull-out, and therefore, no downward extension to the stress-strain curves after failure. Finally, the most striking difference between the results in Tables 2 and 3 is the ultimate tensile strains of the composites. Along the warp direction, the three composites were found to vary strongly in toughness, with a failure strain of $0.85,2.51$ and $4.81 \%$, respectively, for the TT, TU and BU composite. When weft-oriented tension is

Table 3. Tensile properties along the weft direction of steel fabric composites with brittle (B) or tough $(\mathrm{T})$ epoxy matrix and with untreated $(\mathrm{U})$ or treated $(\mathrm{T})$ interface.

\begin{tabular}{lccc}
\hline & TT & TU & BU \\
Mechanical property & Value & Value & Value \\
\hline Young's modulus $E(\mathrm{GPa})$ & $19.0 \pm 1.0$ & $20.7 \pm 1.8$ & $20.4 \pm 1.5$ \\
Yield strength $\sigma_{\mathrm{Y}, 0.1 \%}(\mathrm{MPa})$ & $67.1 \pm 1.4$ & $67.7 \pm 1.4$ & $66.3 \pm 0.8^{\mathrm{a}}$ \\
Yield strain $\varepsilon_{\mathrm{Y}, 0.1 \%}(\%)$ & $0.45 \pm 0.01$ & $0.43 \pm 0.02$ & $0.37 \pm 0.03^{\mathrm{a}}$ \\
Ultimate tensile strength $\sigma_{\text {ult }}(\mathrm{MPa})$ & $84.0 \pm 1.1$ & $87.0 \pm 2.9$ & $71.8 \pm 1.9$ \\
Ultimate tensile strain $\varepsilon_{\text {ult }}(\%)$ & $0.81 \pm 0.06$ & $1.57 \pm 0.58$ & $1.61 \pm 0.60^{\mathrm{b}}$ \\
\hline
\end{tabular}

${ }^{\mathrm{a}}$ Offset yield point at $0.1 \%$ strain is not available. Last data before first stress drop was reported instead.

${ }^{\mathrm{b}}$ Maximum strain value with a stress level within $10 \%$ of the ultimate stress, as recorded by the extensometer. 

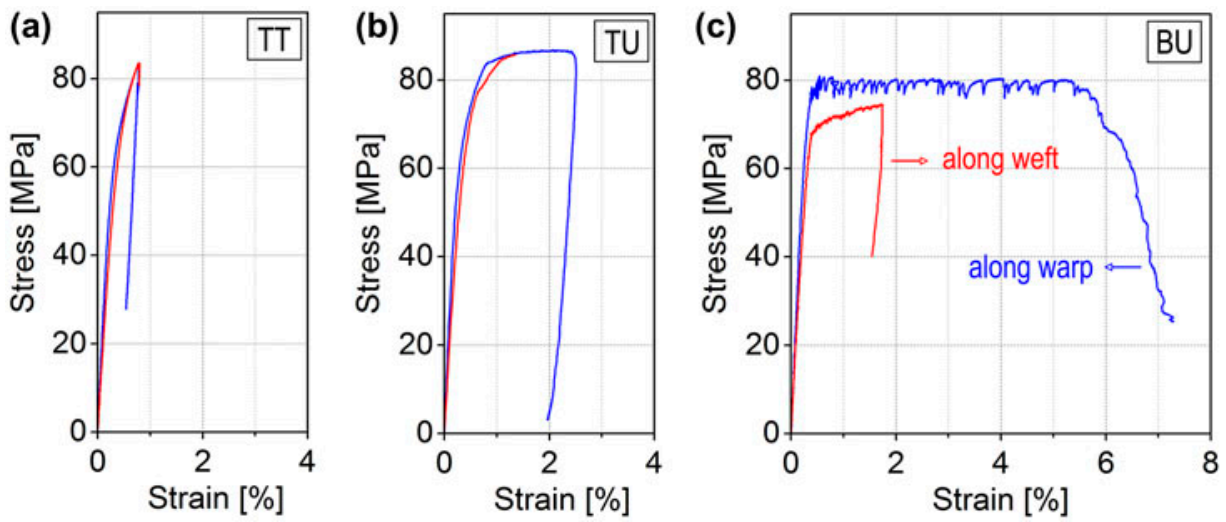

Figure 6. Comparative overview between loading directions for the stress-strain response of the TT (a), TU (b), and BU (c) composite.

applied, the tough composites lose a lot of their advantage and the failure strains come closer together: $0.81,1.57$ and $1.60 \%$, respectively.

\subsubsection{Damage morphology}

A further microscopic investigation was performed to gain insight into the damage mechanisms that lead to final failure of the composites. To this end, the edge of the failed specimens was reconstructed through 3D image stitching, as shown in Figures 7 and 8 for the warp- and weft-oriented composites, respectively. Comparing the trajectories of the load-carrying yarns in both figures illustrates the considerable difference in crimp angle between warp and weft yarns. Also note the difference in density: the average fibre volume fraction in the warp yarns was calculated at $56 \pm 5 \%$, opposed to 30 $\pm 3 \%$ in the weft yarns. In what follows, the nature of the observed damage will be discussed for the three composites separately. In the next section, the micro-mechanisms that govern the composite failure will be discussed.

The TU composites (Tough matrix, Untreated interface) show a lot of cracks after the experiment, as is clear from Figures 7(b) and 8(b). The cracks initiate due to debonding of the weak fibre-matrix interface in the transversal yarns. If the distance between neighbouring fibres is sufficiently small, the interfacial detachments can bridge through the matrix in between. However, if the matrix zone is wide enough, it will arrest the defect through the formation of a matrix cusp, i.e. a local zone of plastic deformation that is characteristic of shear failure.[14] As marked with arrows on Figure 7(d), there are a lot of singular detachments in the transversal weft yarns, because the inter-fibre distance is relatively large. In the transversal warp yarns (Figure 8(d)), the inter-fibre distance is mostly small enough for the detachments to coalesce into well-defined cracks, covering the full height of the yarn. If the distance between neighbouring yarns is small, the cracks can jump from one yarn to another. The matrix pocket typically shows severe plastic deformation in this case. Some cracks are found to extend along the boundary of a transversal yarn, especially in the contact zone with a longitudinal yarn. An example of such a defect is marked on Figure 8(d). Note that this crack debonds the transversal yarn from the matrix, rather than the longitudinal yarn. 


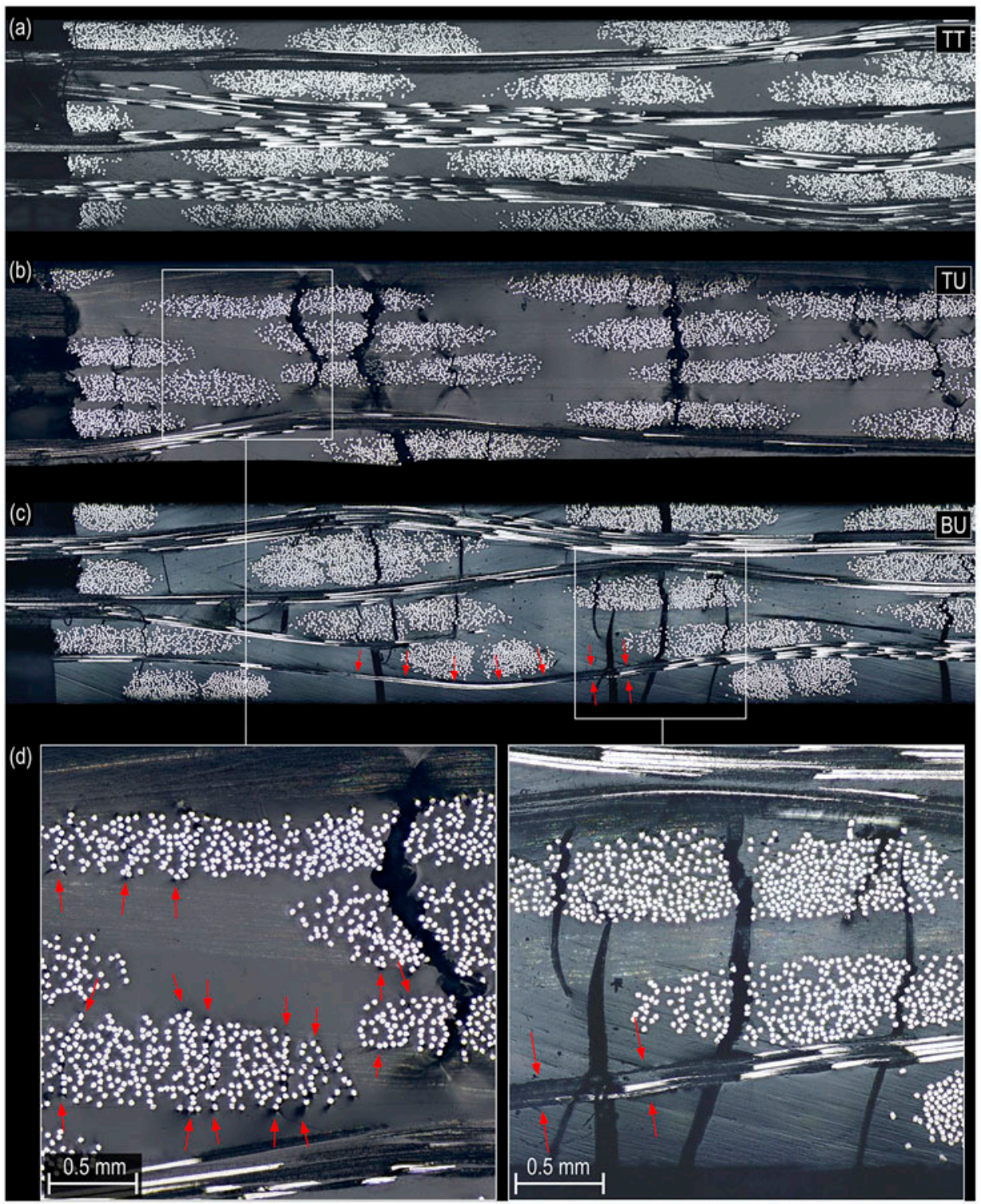

Figure 7. Microscopic reconstruction of the TT (a), TU (b) and BU (c) composite edge after loading along the warp direction with details of the damage morphology (d).

The microscopic images of the TT composites (Tough matrix, Treated interface) on Figures 7(a) and 8(a) clearly prove the effect of the silane treatment. The stress concentrations around the steel fibres must be considerable, because of the stiffness mismatch between the steel fibres and the epoxy matrix and the angular shape of the fibres. Nevertheless, the TT composite edge shows no signs of damage after loading, besides the final crack. Secondary cracks like the one in Figure 8(a) were observed, but only rarely. 


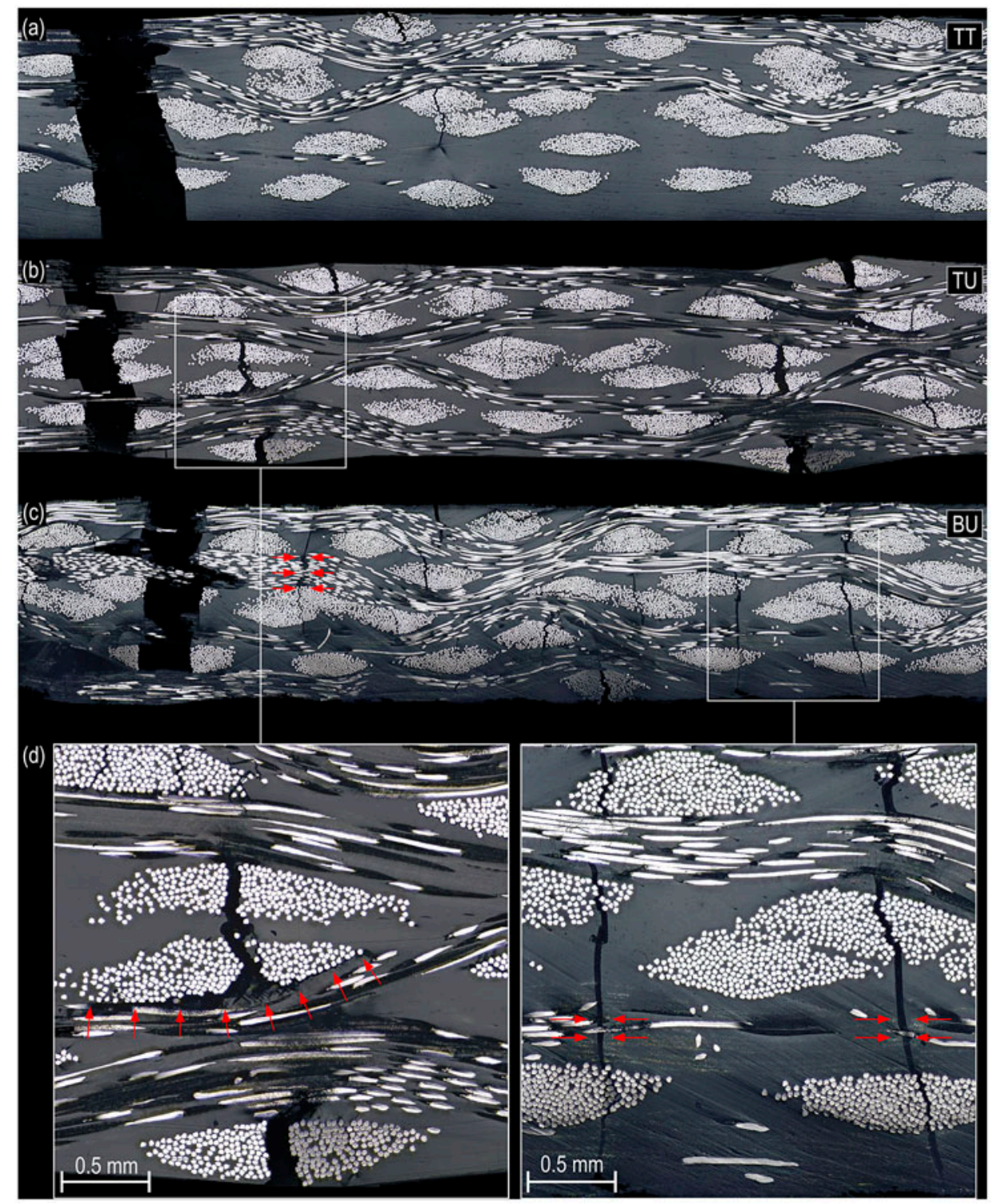

Figure 8. Microscopic reconstruction of the TT (a), TU (b) and BU (c) composite edge after loading along the weft direction with details of the damage morphology (d).

The BU composite (Brittle matrix, Untreated interface) has the same weak fibrematrix interface as the TU composite, but the matrix systems is brittle instead of tough. The brittle matrix is unable to stop any defects, which makes that every small flaw grows into a full crack. This is clearly reflected in the crack morphology on Figures 7(c) and 8(c). There are no signs of local fibre detachments or other small defects that are arrested through matrix cusping. Instead, cracks in the BU composite span the full region between load-bearing yarns. Most of them pass through a transversal yarn, but some run entirely through matrix. This means that the debonding of transversal fibres 
is not the only source of damage initiation in this composite. The way a crack propagates when it comes across a load-carrying yarn is strongly dependent on the loading direction. If a crack encounters a load-bearing warp yarn, the warp yarn typically debonds from the matrix, as marked on Figure 7(c)-(d). The debonding often bridges from one crack to the next, extending over several millimetres. In contrast, if a crack reaches a load-bearing weft yarn, it tends to cross the weft yarn through the matrix, without rupturing or debonding the fibres. This phenomenon is marked on Figure 8(c)-(d).

\section{Mechanisms of damage and failure}

The toughness of the three composites relates to the damage morphology through the micro-mechanics that govern the failure strain. First, note that the steel fibres strain to more than $19 \%$ before failing. The reason why the composites do not attain such a failure strain is because the load-carrying fibres are fixed within the composite structure. The matrix and the transversal yarns work as a mechanical interlock, forcing the loadbearing fibres to deform along with them. The more rigid this transversal structure and the tighter the fibres are fixed within it, the more it restricts the deformation of the load-bearing fibres. Two types of damages were observed in the composites, and both types can contribute to the failure strain. The principles are illustrated schematically in Figure 9. The first type is the transversal damage, ranging from small, local detachments of transversal fibres to fully grown cracks. As long as this damage remains distributed, it softens the transversal structure that interlocks the load-bearing yarns. As soon as it localizes in one section, however, it will onset final failure. The second type of damage is the debonding of load-carrying fibres or yarns. The debonded sections are free to deform to the full plastic potential of the steel fibres, so they can contribute greatly to the deformation capability of the composite. This mechanism cannot occur if the fibre-matrix interface is too strong.[15] Furthermore, it cannot stand alone; it always requires transversal cracks to interrupt the continuity of the transversal structure. The longer the length of the debonding, the more it can contribute to the failure strain by bridging the crack openings. In conclusion, the key to increasing the failure strain

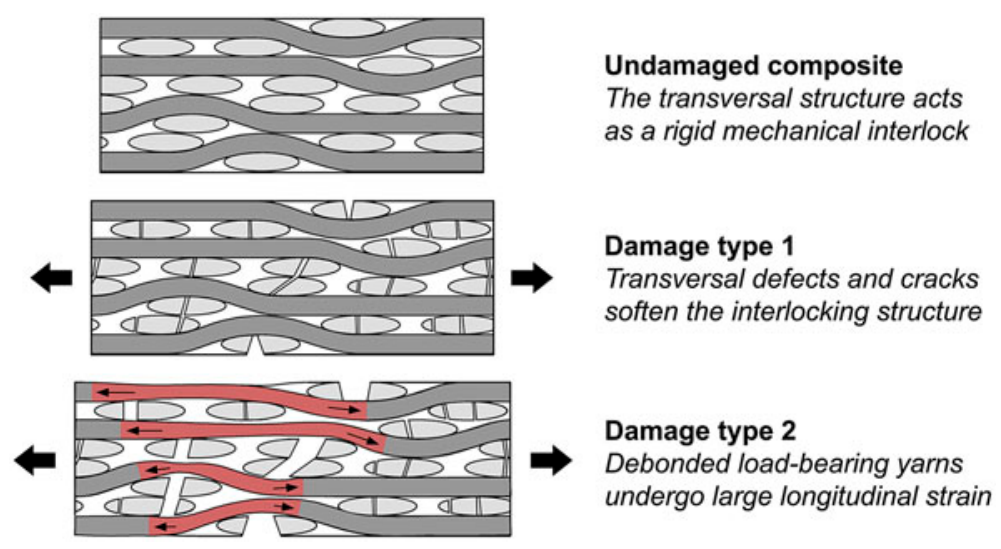

Figure 9. Working principles of how the two types of damage contribute to the composite toughness. 
of the composites is to have as much distributed damage as possible before it starts localizing, and to have long debondings on the load-bearing yarns that are able to bridge the fatal crack.

The principles in Figure 9 apply to the composites under investigation. In the most brittle composite, TT, no damage is accumulated before failure. The strong fibre-matrix adhesion in this composite makes that the interface bond does not fail until a relatively high stress is reached. Thus, when a local defect finally initiates, the global stress level is high enough to facilitate fast crack propagation. As a result, the first crack leads to catastrophic failure. The TU composite has a higher toughness, because there is distributed type 1 damage to soften the material in the transverse direction. The weak fibre/matrix interface in this composite will locally fail at a relatively low global stress level. At that point, the small detachments can easily be cusped by the matrix, because the overall stress is too low to cause sudden rupture. Instead, the cracks open up steadily and a network of cracks arises. There are two arguments for the lower toughness along the weft direction: the stronger undulation of the weft yarns and the denser fibre packing in the warp yarns. As the load-bearing yarns are more undulated, the stress concentrations they cause within the transversal composite structure will be more severe. Further, a densely packed region within the transversal yarns has a higher stiffness, so it will bear more stress. At the same time, the smaller inter-fibre distance in these regions will increase the stress concentration factor on the fibre-matrix interface. If a brittle matrix is used instead of a tough matrix, the damage morphology - and therefore, the toughness, strongly depends on the loading direction. The weft-oriented BU composite is softened by type 1 damage. This damage has a different nature than the type 1 damage in the TU composite, but its effect on the strain-to-failure seems to be the same. The warp-oriented composite additionally shows type 2 damage. Therefore, the transversal cracks can open up further as they are bridged by load-carrying yarns, and the BU composite strains almost twice as far along the warp direction as the TU composite. A possible explanation why the warp yarns debond from the matrix, while the weft yarns break through the matrix, is the difference in fibre volume fraction. The weft yarns can be viewed as a loose collection of separate fibres. If a crack comes across, the fibres act as small separate obstacles that can easily be crossed without changing the crack direction. Because the warp yarns are more compact and have a stronger edge definition, they will act more as one yarn, forcing the cracks to redirect along their boundary. The small distance between the fibres on the yarn border further facilitates debonding.

\section{Conclusions}

This work reports on the influence of the fibre/matrix adhesion strength and the matrix toughness on the strain-to-failure of a 4-harness satin weave composite with ductile steel fibres. The macroscopic mechanical behaviour was related to the microscopically observed damage morphology in order to reveal the mechanisms that govern the toughness. It appears that the woven nature of the reinforcement gives rise to complex interactions between yarns and matrix, with the transversal composite structure acting as a rigid mechanical interlock on the load-carrying yarns. Damage softens the interlock and unbinds the load-bearing yarns, and therefore, it increases the toughness of the composite. This principle explains the counterintuitive observations regarding the influence of the matrix ductility and the fibre/matrix adhesion strength. It was found that selecting a brittle matrix system can lead to a tough composite, because of the evenly 
distributed transversal crack pattern that softens the composite structure. If the loadbearing yarns debond from the matrix, they can bridge the transversal cracks and increase the toughness even more. Enhancing the fibre/matrix adhesion leads to a brittle composite, because it prevents transversal damage prior to failure. These results are fundamentally different from the findings on UD and cross-ply composites.[2,3]

\section{Disclosure statement}

No potential conflict of interest was reported by the authors.

\section{Funding}

This work was supported by SIM-Flanders and conducted in the framework of the SIM Nanoforce Program (Next generation nano-engineered polymer-steel/CNT hybrids) through the NaPoS Project. The stainless steel fibre architecture used in this study was supplied by NV Bekaert SA and the EPIKOTE ${ }^{\mathrm{TM}} 828$ resin was obtained from Brenntag N.V.

\section{References}

[1] Allaer K, De Baere I, Lava P, Van Paepegem W, Degrieck J. On the in-plane mechanical properties of stainless steel fibre reinforced ductile composites. Compos. Sci. Technol. 2014;100:34-43.

[2] Callens MG, Gorbatikh L, Bertels E, Goderis B, Smet M, Verpoest I. Tensile behaviour of stainless steel fibre/epoxy composites with modified adhesion. Composites Part A. 2015;69:208-218.

[3] Callens MG, Gorbatikh L, Verpoest I. Ductile steel fibre composites with brittle and ductile matrices. Composites Part A. 2014;61:235-244.

[4] Bagwell RM, Wetherhold RC. Improvement in fracture toughness of an epoxy/copper composite through the use of various end shaped fibers. Mater. Sci. Eng. A. 2003;361:294-301.

[5] Ghosh AK, Bertels E, Goderis B, Smet M, Van Hemelrijck D, Van Mele B. Optimisation of wet chemical silane deposition to improve the interfacial strength of stainless steel/epoxy. Appl. Surf. Sci. 2015;324:134-142.

[6] Bertels E. Nano-engineered polymer-steel hybrids: chemical and physical compatibilization. Heverlee: KU Leuven; 2015.

[7] Ghosh AK. The interphase in stainless steel-polymer hybrids: characterisation and optimisation of interfacial interaction via surface treatment and nano-modification of the polymer. Brussels: Vrije Universiteit Brussel; 2015.

[8] ASTM D792-13. Standard test methods for density and specific gravity (relative density) of plastics by displacement. West Conshohocken (PA): ASTM; 2013

[9] Vasiliev VV, Morozov E. Advanced mechanics of composite materials. Oxford: Elsevier; 2007.

[10] ASTM standard D3039/D3039M. Standard test method for tensile properties of polymer matrix composite materials. West Conshohocken (PA): ASTM International; 2014. Doi: 10.1520/D3039_D3039M-14. Available from: www.astm.org.

[11] Pinto M, Gupta S, Shukla A. Study of implosion of carbon/epoxy composite hollow cylinders using 3-D digital image correlation. Compos. Struct. 2015;119:272-286.

[12] Pazmino J, Carvelli V, Lomov SV, Van Mieghem B, Lava P. 3D digital image correlation measurements during shaping of a non-crimp 3D orthogonal woven E-glass reinforcement. Int. J. Mater. Form. 2013;7:439-446.

[13] MatchID software [Internet]. Available from: http://www.matchid.org/.

[14] Purslow D. Matrix fractography of fibre-reinforced epoxy composites. Composites. 1986;17:289-303.

[15] Singh S, Srivastava VK, Prakash R. Mechanical properties and morphological studies of C/ C-SiC composites. Mater. Sci. Eng. A. 2012;534:707-710. 